Irena Prosenc Šegula

Universidad de Ljubljana

\title{
INTENTO DE UNA DEFINICIÓN GENÉRICA DEL POEMA RENACENTISTA ITALIANO A LA LUZ DE LAS REFLEXIONES TEÓRICAS DE ORTEGA Y GASSET, LUKÁCS Y BAJTIN
}

La definición genérica de la novela o de lo novelesco es problemática tal cual, sin reparar ya en la forma histórica de la novela a la cual queremos aplicarla. Este artículo propone una contribución a la definición genérica del poema renacentista italiano de los finales del siglo XV y del siglo XVI, a base de las reflexiones de José Ortega y Gasset, Georg Lukács y Mijail Bajtin sobre la novela. La investigación se refiere a las tres obras más importantes de la épica italiana renacentista: Orlando enamorado (Orlando innamorato) de Matteo Maria Boiardo de finales del siglo XV, Orlando furioso de Ludovico Ariosto de la primera mitad del siglo XVI y Jerusalén liberada (Gerusalemme liberata) de Torquato Tasso de la segunda mitad del siglo XVI. Además han sido incluidos algunos poemas descritos en general como menores: Guirón el Cortés (Gyrone il Cortese) de Luigi Alamanni, Amadís (Amadigi) de Bernardo Tasso, Reinaldo (Rinaldo) de Torquato Tasso - todos de la midad del siglo XVI - y Jerusalén conquistada (Gerusalemme conquistata) de Torquato Tasso de finales del siglo XVI. La base de todas estas obras es sin duda el poema caballeresco, ya que sus autores constantemente vuelven a introducir sus motivos y fórmulas estilísticas.

Se suele considerar el poema renacentista italiano como un subgénero de la epopeya ${ }^{1}$ y al mismo tiempo como una forma transitoria entre la epopeya y la novela. No obstante, si analizamos a fondo los poemas tratados en este artículo, descubrimos que el poema renacentista italiano es ya de por sí un género heterogéneo, y que por lo tanto una definición genérica más precisa de los poemas concretos es problemática. Esta dificultad procede del hecho de que estas obras contienen tanto elementos épicos como elementos novelescos; he aquí el punto de referencia para nuestra reflexión sobre la definición de lo épico y de lo novelesco.

Por elementos épicos entendemos los elementos que encuentran su expresión más clara en la epopeya heroica clásica. En lo que concierne a la definición genérica de la epopeya, coincidimos con Bajtin que sostiene que ésta no es problemática (a diferencia de la definición de la novela), puesto que la epopeya es un género antiguo, completamente elaborado, con un canon claro y estable ${ }^{2}$. Sin embargo, para comprender la relación entre lo épico y lo novelesco, hace falta definir la epopeya sobre todo respecto a la novela, y es la definición de esta última la que resulta especialmente conflictiva.

Una definición del género novelesco puede basarse en los criterios formales o en los criterios de contenido; no obstante, tanto unos como otros son meramente relativos. Puesto que los criterios formales ${ }^{3}$ no son suficientes para una distinción entre novela y epopeya, es menester tener en cuenta los criterios de contenido, aún si éstos se refieren

\footnotetext{
${ }^{1}$ Cf. Kos, 1983: 5-6.

2 Cf. Bahtin, 1982: 18.

3 Según Kos la novela se caracteriza por las siguientes cualidades formales: está escrita en prosa, es de larga extensión y predominan los elementos épicos; pero estos criterios no tienen una validez general (Kos, 1983: 23-32 y 1991: 372).
} 
en su mayor parte a las específicas formas históricas de la novela que se desarrollaron desde la antigüedad. Las características de la novela que son identificadas a base de su desarrollo histórico cambian en el tiempo y valen tan sólo para sus formas específicas; por lo tanto no pueden considerarse como cualidades esenciales de este género. Lo problemático de la definición de la novela aún se prolonga al reciente siglo, ya que los teóricos como Ortega y Gasset, Lukács y Bajtin limitan o amplían excesivamente la noción de novela.

A Ortega y Gasset en su ensayo Ideas sobre la novela tan sólo le interesan algunos aspectos de la novela moderna, ya que él mismo subraya que sus constataciones se refieren únicamente a la novela moderna («me refiero tan sólo a la novela moderna $\left.»^{4}\right)$. Él no trata explícitamente ni la definición de la esencia más general de la novela ni la definición de la epopeya, no obstante es posible apoyarse en algunas de sus afirmaciones.

El punto de partida de su artículo es la hipótesis de que la novela está agotada en cuanto a los temas posibles, por lo cual se encuentra en la última fase de su desarrollo: «creo que el género novela, si no está irremediablemente agotado, se halla, de cierto, en su período último y padece una tal penuria de temas posibles, que el escritor necesita compensarla con la exquisita calidad de los demás ingredientes necesarios para integrar un cuerpo de novela» ${ }^{5}$.

Para Ortega y Gasset la esencia de lo novelesco no está en la acción o la trama; esto «no es la sustancia de la novela, sino, al contrario, su armazón exterior, su mero sopor-

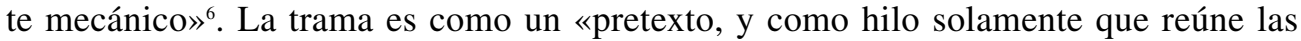
perlas en el collar» ${ }^{7}$, mientras que la esencia de lo novelesco la constituyen la así llamada «psicología imaginaría» de los personajes y la atmósfera creada en la novela: «lo que complace no es tanto el destino o la aventura de los personajes, sino la presencia de éstos. Nos complace verlos directamente, penetrar en su interior, entenderlos, sentirnos inmersos en su mundo o atmósfera $»^{8}$. Según su opinión la esencia de la novela son los personajes, ya que nos interesan más por sí solos que las cosas que les ocurren. Por eso la novela es (y tiene que ser) morosa: «Una narración somera no nos sabe: necesitamos que el autor se detenga y nos haga dar vueltas en torno a los personajes. Entonces nos complacemos al sentirnos impregnados y como saturados de ellos y de su ambiente» ${ }^{9}$. Aunque necesitamos la trama tan sólo como el «soporte mecánico», no podemos desprendernos de ella, ya que para la contemplación es necesaria una mínima acción.

Las conclusiones de Ortega y Gasset no conciernen al conjunto de tipos de novela moderna, ya que a priori excluye de ella lo maravilloso. Es decir, conforme a su tesis de que la novela tenga que crear «la atmósfera», exige de ella «hermetismo», lo que quiere decir que tiene que sacar al lector de su mundo real y «aislarlo» en el mundo de la novela. Por eso tiene que angostar el horizonte del lector, lo que se consigue describiendo la vida cotidiana ${ }^{10}$. La exclusión de lo maravilloso es así para él la esencial cualidad genérica de la novela: «Esta afirmación estética de lo cotidiano y la exclusión rigurosa de todo

${ }^{4}$ Ortega y Gasset, 1995: 42; cf. también 17.

${ }^{5}$ Ortega y Gasset, 1995: 19; cf. también 17 donde compara la novela con una cantera saqueada.

${ }^{6}$ Ortega y Gasset, 1995: 42.

${ }^{7}$ Ortega y Gasset, 1995: 23.

${ }^{8}$ Ortega y Gasset, 1995: 20.

9 Ortega y Gasset, 1995: 23.

${ }^{10}$ Ortega y Gasset, 1995: 43-44. 
lo maravilloso es la nota más esencial que define el género 'novela' en el sentido de esta palabra que importa para el presente ensayo». ${ }^{11}$

Ortega y Gasset en su ensayo tan sólo hace mención de los libros de caballerías, los cuales, por lo menos en cuanto a lo temático, podrían ser el punto de contacto con el poema renacentista italiano. Sin embargo, sus exigencias sobre «la afirmación estética de lo cotidiano» y su negación de lo maravilloso hacen que los libros de caballerías no entren en su concepto de la novela:

Es de esperar que el lector no se rinda al equívoco accidental del lenguaje, que usa el mismo nombre para denominar el libro de caballerías y su opuesto, el Quijote. En rigor, para hallar las condiciones de la novela, en el sentido más actual del término, bastaría con reflexionar sobre cómo puede estar constituida una producción épica que elimina formalmente todo lo extraordinario y maravilloso. ${ }^{12}$

De ahí podemos sacar la conclusión de que el concepto de la novela que tiene Ortega y Gasset tampoco incluye el poema renacentista italiano, ya que los elementos de lo maravilloso están presentes en todos los textos estudiados. Las constataciones de Ortega y Gasset, no obstante, no tienen la validez general para la novela como genéro (ni pretenden tenerla), sino que están históricamente determinadas. Sin embargo, consideramos importante su hipótesis de que tal vez no fuese la esencia de la novela lo que cambió con el tiempo sino el lector. Dice Ortega y Gasset que tal vez para la novela en sus principios lo importante fuera la trama, mientras que actualmente es necesario que el autor nos muestre sus personajes, por eso, «mirada desde hoy, la novela primitiva nos parece más puramente narrativa que la actual $»^{13}$. Pero el autor añade:

Tal vez el primitivo lector de novelas era como es el niño que en unas pocas líneas, en un simple esquema, cree ver, con vigorosa presencia, íntegro el objeto. (...) En tal caso, la novela no habría en rigor variado: sería su actual forma descriptiva, o, mejor, presentativa, tan sólo el nuevo medio que ha sido preciso emplear para obtener sobre una sensibilidad gastada el mismo efecto que en almas más elásticas producía la narración. ${ }^{14}$

Esta hipótesis nos ofrece la posibilidad de una aplicación más amplia, incluyendo las formas literarias más antiguas y tal vez el poema renacentista italiano. Pero el autor no llega a profundizar en ella, ya que no es importante para su línea de reflexión.

Lukács en su tratado Teoría de la novela (Die Theorie des Romans) de modo parecido a Ortega y Gasset se dedica únicamente a algunos tipos de la novela europea de la edad moderna, partiendo del Quijote (al igual que Ortega y Gasset, Lukács lo considera como la verdadera novela). El punto de vista de Lukács es asimismo bastante estrecho en cuanto a la epopeya, ya que, en el sentido estricto, solo hay dos epopeyas para él, la Odisea y la Ilíada ${ }^{15}$. Por eso, no nos es posible tener en cuenta la teoría de Lukács en su conjunto si queremos llegar a una definición ahistórica de los conceptos «épico» y «novelesco»; no obstante, podemos apoyarnos en algunas de sus constataciones.

\footnotetext{
${ }^{11}$ Ortega y Gasset, 1995: 43.

${ }^{12}$ Ortega y Gasset, 1995: 43.

${ }^{13}$ Ortega y Gasset, 1995: 21.

${ }^{14}$ Ortega y Gasset, 1995: 21-22.

${ }^{15}$ Lukács, 2000: 24.
} 
Lukács define la diferencia esencial entre la epopeya y la novela de esta manera: adscribe a la epopeya la totalidad o homogeneidad y a la novela la ausencia de la totalidad o heterogeneidad. Según su teoría el mundo épico forma un todo cerrado donde no hay ruptura entre lo exterior y lo interior. En el centro de la epopeya no hay un destino individual, sino el destino de la comunidad a la cual pertenece el héroe: «El héroe de la epopeya - en sentido estricto - no es nunca un individuo. Desde hace tiempo es considerada la cualidad esencial de la epopeya el que su objeto no sea un destino personal sino el destino de la comunidad.» ${ }^{16} \mathrm{Al}$ contrario del mundo épico, el mundo de la novela es heterogéneo y no cerrado; se caracteriza por la ruptura entre lo exterior y lo interior. La totalidad en la novela no es algo dado, sino algo a lo que la novela aspira ${ }^{17}$, por eso la fundamental actividad del héroe novelesco es la búsqueda, «el viaje del individuo problemático a sí mismo» ${ }^{18}$. Aunque para Lukács ya el hecho mismo de que la búsqueda exista muestra que no es posible conseguir la totalidad. De allí concluye que el desarrollo futuro de la novela no es posible y que su fin en inevitable. Lukács, pues, de manera parecida a Ortega y Gasset, percibe la crisis de la novela, aunque Ortega y Gasset parezca más optimista, ya que ve la crisis de la novela sobretodo en su agotamiento temático y su futuro en la «psicología imaginaría» de los personajes.

En la teoría de Lukács nos interesan especialmente sus reflexiones sobre los libros de caballerías, ya que el poema renacentista italiano se inspira en gran medida en el roman courtois de la Edad Media. Aunque Lukács describe la Edad Media cristiana como la época que llegó a establecer de nuevo la totalidad transcendiendo ésta al mundo de más allá, encuentra en el roman courtois los elementos novelescos que hacen su género problemático - «un caso extraño de la posibilidad de la forma novelesca en una época en la cual la garantía de Dios posibilitó y al mismo tiempo exigió la epopeya $»^{19}$. Los romans courtois son novelescos porque describen un mundo en el cual no hay totalidad; aquí se trata únicamente de «las totalidades buscadas de la vida (...) - de las novelas y no de las epopeyas $»^{20}$. Pero Lukács a continuación descubre que a causa de la superficialidad de los personajes, su búsqueda de la totalidad en los romans courtois es solamente una apariencia de la búsqueda. De ahí resulta que para él los romans courtois solamente reúnen algunas características novelescas: la ausencia de la totalidad, el mundo no acabado, la ausencia de la deidad, mientras que sus personajes no alcanzan el concepto del héroe novelesco ya que, a causa de su superficialidad y su cualidad «decorativa», ellos no son verdaderos héroes problemáticos que aspiren al autoconocimiento y al logro de la totalidad. $\mathrm{Al}$ roman courtois, pues, le falta una de la características esenciales de la novela, según la definición de Lukács, esto es, la aspiración a la totalidad que encuentra su expresión más importante en el héroe problemático. Por ende, según su teoría, los romans courtois, a pesar de los elementos novelescos percibidos, no son verdaderas novelas, sino unas formas que apenas empiezan su evolución hacia la novela.

Lukács en su estudio también menciona de paso los libros de caballerías renacentistas respecto a los cuales, al igual que Ortega y Gasset, tiene una opinión muy negativa

\footnotetext{
${ }^{16}$ Lukács, 2000: 50. V slov.: «Junak epopeje ni - strogo vzeto - nikdar individuum. Od nekdaj so imeli za bistveno znamenje epa, da njegov predmet ni osebna usoda, temveč usoda skupnosti.»

${ }^{17}$ Cf. Lukács, 2000: 43.

${ }^{18}$ Lukács, 2000: 60. El primer héroe de este tipo es para Lukács Don Quijote. V slov.: «potovanje problematičnega posameznika k samemu sebi».

${ }^{19}$ Lukács, 2000: 76. V slov.: «nenavaden primer mo nosti romaneskne forme v dobi, v kateri je poroštvo Boga omogočilo in zahtevala epopejo».

${ }^{20}$ Lukács, 2000: 76-77. V slov.: «iskane totalitete ivljenja (...) - romane in ne epopeje».
} 
(aunque no los analiza en profundidad). Dice que éstos se originan en «el puro y genuino, aunque problemático» poema caballeresco medieval y que en el Renacimiento ya no son un género justificado desde el punto de vista de la historia de filosofía, sino una forma muerta con la función de ser una lectura de diversión. ${ }^{21}$ Mientras que para él el roman courtois medieval se encuentra a mitad de camino entre la novela y la epopeya, en los libros de caballerías no ve señales de esta transición, ya que, como un género muerto, no puede anunciar la transición de un género al otro sino que solamente puede significar el fin de un género.

Las constataciones de Lukács son, al igual que las de Ortega y Gasset, históricamente limitadas y no tienen la validez general para la novela en cuanto a género. Los intentos de definiciones de la esencia de la novela respecto a los cuales estamos obligados a constatar que sus criterios solo valen para determinados tipos de la novela y no para la novela en general, nos llevan fácilmente a concordar con una de las tesis fundamentales de Bajtin que dice que la esencia de la novela es indefinible. Justamente basándose en la tesis de que las características del género novelesco no son permanentes, Bajtin se opone a las afirmaciones de Ortega y Gasset y de Lukács sobre el fin de la novela; según su opinión, pues, la novela como género todavía sigue en evolución, es más, tiene ilimitadas posibilidades de evolución. Sin embargo, Bajtin no respeta su propia tesis original, ya que a pesar de afirmar su indefinibilidad, intenta llegar a una definición, y eso de manera parecida a muchos otros teóricos: comparándola con la epopeya.

Según Bajtin una de las esenciales características de la novela es el contacto máximo con la coetaneidad (o sea contemporaneidad), en su no acabamiento. ${ }^{22}$ La epopeya, por otro lado, se caracteriza por la perfecta distancia épica ya que el mundo épico se separa de la contemporaneidad (es decir, del tiempo del autor y de los lectores) por sus valores y por el curso del tiempo. Así como Lukács también Bajtin sostiene que el mundo épico es acabado, cerrado y no cuestionable.

Bajtin considera también los libros de caballerías para los cuales sostiene (por lo menos para los primeros libros de caballerías en verso) que se encuentran en el límite entre la epopeya y la novela. Aunque al constatar que el roman courtois es una forma transitoria se acerca a Lukács, sus opiniones al respecto son completamente divergentes. Lukács, pues, está demostrando que el roman courtois se está acercando a la novela, mientras que Bajtin, justamente al contrario, afirma que se está acercando a la epopeya. Para Lukács el mundo del roman courtois es heterogéneo porque está separado del mundo transcendental y justamente por eso es novelesco, mientras que para Bajtin este mundo es entero ya que se rige por la norma de lo casual y lo maravilloso, y esta «enteridad» es, según Bajtin, característica para el mundo épico. Así llegamos al punto donde Bajtin, aunque desde diferente perspectiva, de modo parecido a Lukács, distingue entre la epopeya y la novela según el criterio del «acabamiento»o «lo cerrado» del mundo épico o sea el criterio de «no acabamiento» del mundo novelesco. Pero precisamente en el ejemplo del roman courtois medieval vemos que son viables diferentes interpretaciones del criterio de la totalidad o «enteridad» y que se puede llegar a conclusiones completamente divergentes. La afirmación de Bajtin, según la cual lo maravilloso es característico para la epopeya, concuerda con la exigencia de Ortega y Gasset de que hay que excluir rigurosamente

\footnotetext{
${ }^{21}$ Lukács, 2000: 76.

${ }^{22}$ Bahtin, 1982: 15.
} 
lo maravilloso ${ }^{23}$ de la novela. Si aplicamos ambas afirmaciones al poema renacentista italiano, podemos llegar a la conclusión de que, según este criterio, se trata de una epopeya y no de una novela, mientras que según Lukács podemos deducir que es solamente un género muerto, sin definiciones lo más pormenorizadas posibles.

En cuanto a la teoría de la novela de Bajtin, como más problemático se muestra justamente su suposición fundamental, esto es, la tesis sobre la indefinibilidad de la novela, es decir, sobre la inexistencia de la no mudanza de la esencia de la novela. Pues, si deseamos seguir estrictamente esta tesis, no podemos definir a la novela ni con los criterios formales ni mucho menos con los criterios de contenido. El ensayo de Ortega y Gasset es, por otro lado, históricamente limitado y tan sólo concierne a la novela moderna, y es por consiguiente solamente parcialmente aplicable a cualesquiera de otras formas de la novela. También es discutible el criterio de totalidad de Lukács, de manera convincente refutado por Janko Kos. Kos sostiene que ese criterio no es apropiado para distinguir entre la epopeya y la novela, puesto que tanto la novela como la epopeya presentan la totalidad de un mundo ${ }^{24}$. Para esto se apoya en las reflexiones de Hegel sobre la epopeya y la novela; éste ve la totalidad tanto en el mundo épico como en el mundo novelesco; mientras que la epopeya presenta la totalidad del mundo heroico, la novela presenta la totalidad del mundo burgués ${ }^{25}$.

Las tres teorías más importantes de la novela del siglo XX pues sólo nos pueden ayudar de manera limitada en nuestras reflexiones sobre la definición del género del poema renacentista italiano. En primer lugar, porque el poema renacentista italiano es una forma de género heterogénea y transitoria, y en segundo lugar, porque las tres teorías o restringen demasiado el concepto de la novela a sus concretas formas históricas, o lo amplían excesivamente.

\footnotetext{
${ }^{23}$ Cf. Bahtin, 1982: 278.

${ }^{24}$ Kos, 1991: 371-375.

${ }^{25}$ Hegel subraya explícitamente que tanto la novela como la epopeya necesitan la totalidad de un concepto del mundo y de la vida (Hegel, 1975: III, 498).
} 


\section{BIBLIOGRAFÍA}

Alamanni, Luigi (1548): Gyrone il Cortese di Luigi Alamanni al christianissimo, et invittissimo re Arrigo Secondo. Rinaldo Calderio, \& Claudio suo figliolo (eds.). París: Calderio.

Ariosto, Ludovico (1992): Orlando furioso. Lanfranco Caretti (ed.). Turín: Einaudi.

Boiardo, Matteo Maria (1995): Orlando innamorato. Riccardo Bruscagli (ed.). Turín: Einaudi.

Tasso, Bernardo (1560): L'Amadigi del S. Bernardo Tasso. A l'invittissimo, e catolico re Filippo.

Vinegia: Giolito de' Ferrari.

Tasso, Torquato (1934): Gerusalemme conquistata. Luigi Bonfigli (ed.). Bari: Laterza.

Tasso, Torquato (1993): Gerusalemme liberata. Lanfranco Caretti (ed.). Turín: Einaudi.

Tasso, Torquato (1990): Rinaldo. Michael Sherberg (ed.). Ravenna: Longo.

Bahtin, Mihail (1982): Teorija romana. Izbrane razprave (traducción de Drago Bajt). Ljubljana: Cankarjeva založba.

Hegel, Georg Wilhelm Friedrich (1975): Estetika I, II, III (traducción de Nikola Popović). Beograd: Beogradski izdavačko-grafički zavod (título original: Vorlesungen über die Ästhetik).

Kos, Janko (1983): Roman. Ljubljana: Državna založba Slovenije.

Kos, Janko (1991): «Ep in roman na Slovenskem». Slavistična revija, 39, 4: 371-389.

Lukács, Georg (2000): Teorija romana, Filozofskozgodovinski poskus o formah velike epike (traducción de Tomo Virk). Ljubljana: Literarno-umetniško društvo Literatura (título original: Die Theorie des Romans, Ein geschichtsphilosophischer Versuch über die Formen der großen Epik).

Ortega y Gasset, José (1995): «Ideas sobre la novela». En: Ideas sobre el teatro y la novela. Madrid: Revista de Occidente en Alianza Editorial, 13-56.

\section{POSKUS ZVRSTNE OPREDELITVE ITALIJANSKEGA RENESANČNEGA EPA V LUČI TEORETSKIH RAZMIŠLJANJ ORTEGA Y GASSETA, LUKÁCSA IN BAHTINA}

Članek obravnava zvrstno opredelitev italijanskega epa konec 15. stoletja in v 16. stoletju, pri čemer se opre na ugotovitve treh najvidnejših teoretikov 20. stoletja, ki so razmišljali o bistvu romana. Zvrstna opredelitev italijanskega renesančnega epa je problematična, saj gre za prehodno obliko med epom in romanom, poleg tega pa obravnavani epi še zdaleč niso zvrstno enotni. Ortega y Gasset, Lukács in Bahtin lahko vsi delno prispevajo k zvrstni opredelitvi renesančnega epa, vendar pa se na nikogar od njih ni moč opreti v celoti. Ortega y Gasset in Lukács obravnavata historično omejene oblike romana (zgolj novoveški roman), medtem ko Bahtin izhaja iz predpostavke, da je roman neopredeljiv, ki pa se je niti sam ne drži dosledno. Zato lahko na podlagi njihovih ugotovitev sicer opredelimo nekatere vidike renesančnega epa, ne moremo pa oblikovati splošne teorije epa in romana, ki bi jo lahko aplicirali nanj. 